\title{
The knowledge of medical students about aging and its related factors in Yazd,
}

\section{Iran}

Kian Nourozi Tabrizi ${ }^{1, *}$, Maedeh Mortezanasab ${ }^{1}$, Farahnaz Mohammadi-Shahboulaghi ${ }^{1}$, Mostafa Shokati Ahmad Abad ${ }^{2}$, Mahdi Noroozi ${ }^{1}$

${ }^{1}$ University of Welfare and Rehabilitation, Tehran, Iran

${ }^{2}$ Department of Nursing, School of Nursing and Midwifery, Research Center for Nursing and Midwifery Care, Shahid Sadoughi University of Medical Sciences, Yazd, Iran

*. Corresponding author: Kian Nourozi Tabrizi. University of Welfare and Rehabilitation, Tehran, Iran. Tel: +989123476590, E-mail: norozi-kian@uswr.ac.ir.

Cite this article: Nourozi Tabrizi, K.; Mortezanasab, M.; Mohammadi-Shahboulaghi, F.; Shokati Ahmad Abad, M.; Noroozi, M. The knowledge of medical students about aging and its related factors in Yazd, Iran. Int J Epidemiol Health Sci 2021;2(11):e21. Doi:10.51757/IJEHS.2.11.2021.245812.

\begin{abstract}
Background: Medical students must have sufficient expertise to provide health services to the old as the global population of the elderly grows. Few research, however, have looked into this issue among medical, health, and nursing students. As a result, the purpose of this study was to look into the knowledge of medical, health, and nursing students on aging and related variables.

Methods: In the year 2020, a cross-sectional study was done in Yazd, Iran. The research community was founded by Yazd University of Medical Sciences students. A total of 105 students from medical, health, and nursing were needed for the study. Two tools were used to collect data. a) A list of demographic characteristics Age, gender, level of education, and b) The Facts on Aging Quiz are among the items on this checklist (FAQI). FAQI is made up of 25 things in four dimensions, each of which can be answered with one of three options: "correct," "don't know," or "false." A higher score suggests a better position and a greater understanding of aging facts.

Results: Students were 29 years old on average. Women made up almost $75 \%$ of those who took part. Only over a quarter of the attendees went to conferences and seminars on senior health. The majority of students in all three areas (medicine, health, and nursing) had never volunteered with the elderly before. Medical, nursing, and health students scored 11.093.4, 8.83.1, and 11.82.8 out of a possible 25 points on their understanding of aging facts, respectively. Only the area of study was statistically associated to the mean score of facts of aging among the demographic variables, indicating that the knowledge score of medicine and nursing students was lower than that of health students.
\end{abstract}

Conclusion: The students that took part in this study lacked appropriate awareness of the facts of aging. Students' understanding in this area must be increased through the implementation of relevant educational programs.

Keywords: Medical students, Aging, Elderly care, Elderly health, Knowledge 


\section{Introduction}

One of the most pressing concerns confronting international health-care systems is population aging $(1,2)$. Between 2015 and 2050, the percentage of the global population aged 60 and up will nearly double, from $12 \%$ to $22 \%$. (3). By the year 2020, the number of persons aged 60 and more will outweigh youngsters under the age of five. In 2050, $80 \%$ of the world's elderly will live in low- and middle-income countries (4). Iran, like many other countries, is seeing an increase in its older population as living standards improve (5). According to the most recent report on the number of old people in Iran, 8.2 percent of the population is above the age of 65 . (6). Iran's old population is expected to reach 10.5 percent by 2050 , according to estimates.

Attending to the health requirements of the elderly is not just a moral obligation, but also a societal need (8). The rising older population necessitates special attention nowadays (9). Health care providers must be sufficiently knowledgeable of the physical and psychological changes of the elderly to give appropriate assistance to this group of persons in the community (4). Knowing the facts about aging entails enlightening people about the elderly's medical, psychological, social, and economic components, as well as common misunderstandings about old age that might influence people's conduct $(10,11)$. Physical, emotional, and social realities, as well as misunderstandings regarding the aging process, are among the facts of aging (12). Inadequate adaptation of care offered to the elderly due to a lack of fundamental information about normal physiological changes in old age can put the elderly at risk (2). Previous studies on health-care team members' understanding of aging facts have revealed interesting results. In a study of nurses, Ravanipour and colleagues found that nurses have a moderate understanding of the facts of aging (2). In a review research, Alamri and colleagues found that health care team members lacked appropriate understanding on the facts of aging (13).

Medical students must give health care to the elderly both throughout their studies and after graduation, therefore they must be well-versed in the facts of aging. However, there are few studies that look at medical students' understanding of aging facts. The majority of past research has focused solely on nursing students. Meanwhile, other groups of medical students work with the elderly and offer them with health services. As a result, it's vital to assess their competence in this area. The current study was conceived and executed with this goal in mind, to test medical students' awareness of aging facts.

\section{Method}

This cross-sectional study took place in Yazd in 2020. The research community was founded by Yazd University of Medical Sciences students. Based on the findings of the Allen and colleagues investigation, a sample size of 105 students was necessary (14). Stratified sampling was used to collect data. Students choose from the fields of medicine, nursing, and public health engineering using a table of random numbers.

In order to be considered, applicants had to be enrolled at Yazd University of Medical Sciences in one of the departments of medicine, nursing, or public health engineering, as well as have a smartphone. The following criteria were fulfilled: One student refused to take part in the research. Students who return incomplete questionnaires for any reason are also excluded.

\section{Data collection}

The researchers contacted Yazd University of Medical Sciences' Vice-Chancellor for Education and got a list of medical, nursing, and public health engineering students. Then, from each field, the desired number of samples was chosen, and they were called by phone. If students are happy with their decision to participate in the study, a link to the electronic questionnaire was delivered to them via software such as Telegram, WhatsApp, or email.

\section{Data collection tools}

Data was gathered using two different technologies. a) a demographic information checklist including questions regarding age, gender, marital status, level of education, attendance at aging workshops, and experience caring for the elderly; and b) facts about the Aging Quiz (FAQI). This questionnaire was devised by Erdman Palmore to test people's knowledge of the medical, psychological, social, and economic aspects of aging, as well as aging myths (14). This questionnaire has been utilized by geriatrics researchers from throughout the world. This questionnaire has 25 items in four dimensions, each of which can be responded with one of three options: "correct," "do not know," or "false." A higher score suggests a better position and a greater understanding of aging facts. In Iran, this questionnaire has previously been translated, and its validity and reliability have been shown. Cronbach's alpha (0.81) was reported by Heravi and colleagues for this questionnaire (11). 


\section{Ethical considerations}

The ethics committee of the University of Social Welfare and Rehabilitation Sciences provided the code of ethics for this investigation (IR.USWR.REC.1399; 146). The researchers evaluated all aspects of medical research ethics, including getting informed consent, independence in participating in and quitting the study, and information confidentiality at all stages of the study.

\section{Data analysis}

SPSS software (version 24) was used for analyzing the data. The mean and standard deviation used for quantitative variables description. For qualitative data, frequency and percentage tables were employed. The data was analyzed and the correlation between the variables was determined using Pearson and Chisquare tests.

\section{Results}

The students' average age was 29.3 years. Women made up about $75 \%$ of the participants. Only over a quarter of the attendees went to conferences and seminars about senior health. The aged care centers or rehabilitation centers were visited by a big number of students in the fields of medicine and nursing, but the majority of students in the field of health had not. The majority of students in all three fields had no prior experience volunteering to care for older persons, whether they were healthy or ill. Table 1 shows demographic data.

Nursing, medicine, and health students scored 11.093.4, 8.83.1, and 11.82.8, respectively, on their understanding of aging facts. Only the area of study was statistically associated to the mean score of knowledge about the facts of aging among the demographic variables, with the score of knowledge in medicine and nursing students being lower than that of health students (p0.05). The responses of medicine, nursing, and health students to the questionnaire items are provided in table two (Table 2).
Table 1. Demographics characteristics of participants

\begin{tabular}{|l|l|l|l|}
\hline Item & Number & Percent \\
\hline \multirow{2}{*}{$\begin{array}{l}\text { Students } \\
\text { gender }\end{array}$} & Male & 26 & $24.8 \%$ \\
\cline { 2 - 4 } & Female & 79 & $75.2 \%$ \\
\hline \multirow{2}{*}{$\begin{array}{l}\text { Marital } \\
\text { status }\end{array}$} & Single & 32 & $30.5 \%$ \\
\cline { 2 - 4 } & Married & 73 & $69.5 \%$ \\
\hline \multirow{2}{*}{$\begin{array}{l}\text { Level of } \\
\text { education }\end{array}$} & Graduate & 32 & $30.5 \%$ \\
\cline { 2 - 4 } & Master & 22 & $21 \%$ \\
\cline { 2 - 4 } & PhD & 51 & $48.5 \%$ \\
\hline \multirow{2}{*}{$\begin{array}{l}\text { Field of } \\
\text { study }\end{array}$} & $\begin{array}{l}\text { Health } \\
\text { engineering }\end{array}$ & 12 & $39 \%$ \\
\cline { 2 - 4 } & Nursing & 52 & $49.5 \%$ \\
\cline { 2 - 4 } & Medicine & 41 & $11.4 \%$ \\
\hline
\end{tabular}


Table 2. The mean score response of medical sudents to the questionnaire items

\begin{tabular}{|c|c|c|c|c|c|c|c|}
\hline Question & \multicolumn{2}{|c|}{ Nursing } & \multicolumn{2}{|c|}{ Medicine } & \multicolumn{2}{|r|}{ Health } & P value \\
\hline $\begin{array}{l}\text { The majority of old people* are senile (i.e. } \\
\text { defective memory, disoriented, or } \\
\text { demented). }\end{array}$ & $\mathrm{N}=52$ & Mean $=0.25$ & $\mathrm{~N}=41$ & Mean $=0.27$ & $\mathrm{~N}=12$ & Mean $=0.17$ & \multirow{14}{*}{$P=0.031$} \\
\hline . All five senses tend to decline in old age. & $\mathrm{N}=52$ & Mean $=0.35$ & $\mathrm{~N}=41$ & Mean $=0.32$ & $\mathrm{~N}=12$ & Mean $=0.09$ & \\
\hline $\begin{array}{l}\text { Most old people have no interest in, or } \\
\text { capacity for,sexual relations }\end{array}$ & $\mathrm{N}=52$ & Mean $=0.43$ & $\mathrm{~N}=41$ & Mean $=0.40$ & $\mathrm{~N}=12$ & Mean $=0.17$ & \\
\hline $\begin{array}{l}\text { Lung vital capacity tends to decline in old } \\
\text { age }\end{array}$ & $\mathrm{N}=52$ & Mean $=0.79$ & $\mathrm{~N}=41$ & Mean $=0.71$ & $\mathrm{~N}=12$ & Mean $=0.67$ & \\
\hline $\begin{array}{l}\text { The majority of old people feel miserable } \\
\text { most of the } \\
\text { time. }\end{array}$ & $\mathrm{N}=52$ & Mean $=0.18$ & $\mathrm{~N}=41$ & Mean $=0.18$ & $\mathrm{~N}=12$ & Mean $=0.17$ & \\
\hline Physical strength tends to decline in old age & $\mathrm{N}=52$ & Mean $=0.89$ & $\mathrm{~N}=41$ & Mean $=0.83$ & $\mathrm{~N}=12$ & Mean $=0.84$ & \\
\hline $\begin{array}{l}\text { At least one-tenth of the aged are living in } \\
\text { long-stay institutions (i.e. nursing homes, } \\
\text { mental hospitals, } \\
\text { homes for the aged, etc.). }\end{array}$ & $\mathrm{N}=52$ & Mean $=0.43$ & $\mathrm{~N}=41$ & Mean $=0.25$ & $\mathrm{~N}=12$ & Mean $=0.34$ & \\
\hline $\begin{array}{l}\text { Aged drivers have fewer accidents per driver } \\
\text { than } \\
\text { drivers under age } 65 \text {. }\end{array}$ & $\mathrm{N}=52$ & Mean $=0.41$ & $\mathrm{~N}=41$ & Mean $=0.35$ & $\mathrm{~N}=12$ & Mean $=0.50$ & \\
\hline $\begin{array}{l}\text { Most older workers cannot work as } \\
\text { effectively as } \\
\text { younger workers }\end{array}$ & $\mathrm{N}=52$ & Mean $=0.72$ & $\mathrm{~N}=41$ & Mean $=0.59$ & $\mathrm{~N}=12$ & Mean $=0.67$ & \\
\hline $\begin{array}{l}\text { About } 80 \% \text { of the aged are healthy enought } \\
\text { to carry out their normal activities }\end{array}$ & $\mathrm{N}=52$ & Mean $=0.49$ & $\mathrm{~N}=41$ & Mean $=0.42$ & $\mathrm{~N}=12$ & Mean $=0.67$ & \\
\hline $\begin{array}{l}\text { Most old people are set in their ways and } \\
\text { unable to } \\
\text { change }\end{array}$ & $\mathrm{N}=52$ & Mean $=0.60$ & $\mathrm{~N}=41$ & Mean $=0.44$ & $\mathrm{~N}=12$ & Mean $=0.50$ & \\
\hline $\begin{array}{l}\text { Old people usually take longer to learn } \\
\text { something new }\end{array}$ & $\mathrm{N}=52$ & Mean $=0.87$ & $\mathrm{~N}=41$ & Mean $=0.93$ & $\mathrm{~N}=12$ & Mean $=0.92$ & \\
\hline $\begin{array}{l}\text { It is almost impossible for most old people } \\
\text { to learn } \\
\text { something new. }\end{array}$ & $\mathrm{N}=52$ & Mean $=0.91$ & $\mathrm{~N}=41$ & Mean $=0.91$ & $\mathrm{~N}=12$ & Mean $=0.84$ & \\
\hline $\begin{array}{l}\text { The reaction time of most old people tends } \\
\text { to be slower than reaction time of younger } \\
\text { people. }\end{array}$ & $\mathrm{N}=52$ & Mean $=0.89$ & $\mathrm{~N}=41$ & Mean $=0.86$ & $\mathrm{~N}=12$ & Mean $=0.84$ & \\
\hline
\end{tabular}




\section{Discussion}

The findings of this study revealed that, in general, medical, nursing, and health students lack appropriate awareness of aging facts. Furthermore, when compared to the other two groups, this lack of understanding was more prevalent among medicine and nursing students.

In developing countries, the old population is expanding, and medical students need to be better educated about aging. The pupils in this study, on the other hand, lacked sufficient understanding about the facts of aging. This could make providing high-quality care to the elderly more difficult in the future. Previous research on awareness of aging facts has focused on nurses and physicians rather than students, particularly medicine and health students. Researchers in Serbia analyzed the expertise of 130 students studying medical, nursing, and rehabilitation. The researchers used Palmore's Facts on Aging Quiz for this. The findings of that study revealed that students have a moderate understanding of aging facts, which is similar to the findings of the current study (15). During their studies, medical students should learn more about the elderly. According to previous research, medical students are more involved with geriatric care during their studies, which helps them become more aware of aging realities (16). Previous research has showed that medical students have a favorable attitude toward the elderly (17). Given medical students' positive attitudes toward the old, it appears that if they receive adequate instruction about the elderly, they will absorb it well and expand their knowledge on the subject.

Medicine and nursing students have lower understanding than the other health students, according to the results of the study. Two investigations published in 2020 and 2019 in other countries found that nursing students in those nations lacked appropriate understanding regarding aging facts, similar to the findings of this study $(4,18)$. This is a problem that must be addressed. In recent years, the field of geriatric medicine and nursing has grown in Iran, and students now have the possibility to pursue further education in this subject. However, it appears that additional planning and interventions to educate undergraduate medicine and nursing students about aging and caring for healthy and ill old persons are needed. In this context, improving educational curricula, particularly clinical education, as well as organizing frequent training courses on aging can be beneficial.

\section{Conclusion}

The students that took part in this study lacked appropriate awareness of the facts of aging. Given that these students will be entering the health-care system in the future and will be responsible for providing health services to the elderly in their communities, it is critical that they become more aware of this issue. Due to the rise in the senior population, medical students' educational programs in the area of the elderly must be given more emphasis. Further research in this area is recommended due to a paucity of studies. It is also suggested that additional groups of medical students be tested on their knowledge of aging facts.

\section{Limitations}

For this study, only students studying medicine, nursing, or health were chosen. As a result, it's impossible to extrapolate the results to other medical students.

\section{References}

1. Oksuzyan, A., Höhn, A., Krabbe Pedersen, J., Rau, R., Lindahl-Jacobsen, R., Christensen, K. Preparing for the future: The changing demographic composition of hospital patients in Denmark between 2013 and 2050. PLoS ONE. 2020;15(9):e0238912.

2. Ravanipour M, Dadaeen A, Jahanpour F, Husseini S. Measuring nurses' knowledge about the facts of aging period in educational hospitals of Bushehr in 2012. J Geriatr Nurs 2015;1(2):55-67.

3 . https://www.who.int/news-room/factsheets/detail/ageing-and-health.

4. Muhsin, A.A., Munyogwa, M.J., Kibusi, S.M., Seif, S.A. Poor level of knowledge on elderly care despite positive attitude among nursing students in Zanzibar Island: findings from a cross-sectional study. BMC Nursing. 2020;19(1):96.

5. Naseh, L., Shaikhy, R., Rafiei, H. General SelfEfficacy and Associated Factors among Elderly Residents of Nursing Home. J Holist Nurs Midwifery 2016;26(2):90-97.

6. Farokhnezhad Afshar P, Asgari P, Shiri M, Bahramnezhad F. A Review of the Iran's elderly status according to the census records. Galen Med J 2016;5(1):1-6.

7. Manoochehry, S., Rasouli, H. Iranian Population Policy and Aging: New Health Concerns. Int J Travel Med Glob Health 2017;5(2): 70-71.

8. Hosseiny, R. S., Alijanpour Agha Maleki, M., Etemadifar, S., Rafiei, H. Religious attitudes and spiritual health among elderly inpatient adults in Shahrekord hospitals. Jorjani Biomed J 2016;4 (1):5665.

9. Packpour, V., Allahverdi Mamaghani, R., Kianian, T. Comparison of Knowledge and attitude of Nursing Students and Nurses towards facts of aging period in 2019. J Gerontol 2020;5 (1):48-58. 
10. Asgarizadeh Mahani, M., Arab, M., Mohammadalizade, S., Haghdoost, A. Staff nurses knowledge of aging process and their attitude toward elder people. Iran J Nurs 2008;21(55):19-27.

11. Rejeh, N., Heravi-Karimooi, M,, Montazeri. A, Foroughan, M. Psychometric properties of the Iranian version of the Facts on Aging Quiz (FAQI). Payesh 2012;11(2):245-251.

12. Yang, Y., Xiao, L.D., Ullah, S., Deng, L. General practitioners' knowledge of ageing and attitudes towards older people in $\mathrm{C}$ hina. Australas J Ageing 2015;34(2):82-7.

13. Alamri, B.H., Xiao, L.D. Health professionals' knowledge and attitudes toward older people in primary care in Saudi Arabia. Saudi Med J 2017;38(3):229-236.

14. Palmore, E.B. Facts on aging: a short quiz.

Gerontologist 1977; 17(4): 315-20.

15. Milutinović, D., Simin, D., Kacavendić, J., Turkulov, V. KNowledge and attitudes of health care science students toward older people. Med Pregl 2015;68(11-12):382-6.

16. van Zuilen, M.H., Rubert, M.P., Silverman, M., Lewis, J. Medical Students' Positive and Negative Misconceptions About the Elderly. Gerontol Geriatr Educ 2001;21(3):31-40.

17. Abolfathi Momtaz, Y., Mousavi-Shirazi, F., Mollaei, P., Delbari, A. Attitude of Medical Sciences Students toward Older Adults in Iran, 2017. Open Psychol J 2019;12:40-45.

18. Ghimire, S., Shrestha, N., Callahan, K.E., Nath, D., Baral, B.K., Lekhak, N., Singh, D.R. Undergraduate nursing students' knowledge of aging, attitudes toward and perceptions of working with older adults in Kathmandu Nepal. Int $\mathbf{J}$ Nurs Sci 2019;6(2):204-10. 